\title{
Une vie
}

Alastair B. Duncan, David Zemmour, Jean H. Duffy et Bérénice Bonhomme

\section{(2) OpenEdition}

Journals

Édition électronique

URL : https://journals.openedition.org/ccs/1425

DOI : $10.4000 /$ ccs. 1425

ISSN : 2558-782X

Éditeur :

Presses universitaires de Rennes, Association des lecteurs de Claude Simon

Édition imprimée

Date de publication : 30 août 2018

Pagination : 17-18

ISBN : $978-2-7535-7489-2$

ISSN : $1774-9425$

Référence électronique

Alastair B. Duncan, David Zemmour, Jean H. Duffy et Bérénice Bonhomme, « Une vie », Cahiers Claude Simon [En ligne], 13 | 2018, mis en ligne le 30 août 2019, consulté le 25 avril 2022. URL : http:// journals.openedition.org/ccs/1425; DOI : https://doi.org/10.4000/ccs.1425 


\section{UNE VIE}

Alastair B. DUNCAN, David ZEMMOUR, Jean H. DUFFY, Bérénice BONHOMME ${ }^{1}$

Réa Simon, née Karavas, est décédée à Paris le 22 septembre 2017.

C'était une personne exceptionnelle. Réa Simon est née en Grèce en 1928 dans une famille aisée et surtout cultivée. Elle suit des études de français et de philosophie. En 1956, elle rencontre Kostas Axelos, de passage à Athènes pour la première fois après avoir dû fuir son pays pour la France en 1945. En 1957, ils rejoignent la revue Arguments créée un an plus tôt et publiée par les Éditions de Minuit. Réa en devient secrétaire, correctrice d'épreuves et même distributrice auprès des kiosques parisiens.

Elle n’a jamais perdu son léger accent grec, mais sa maîtrise du français était parfaite.

Réa a rencontré Claude Simon pour la première fois en 1962 lors d'un dîner à l'époque de la parution du Palace. C'est le coup de foudre. Ensemble, ils voyagent en Italie. Lui quitte définitivement sa femme, elle son mari. Ils s'installent à Perpignan dans la maison de famille de Claude rue de la Cloche d'or, puis à Salses dans la maison qui allait devenir pendant près de quarante ans leur quartier d'été. À Paris, ils achètent un appartement Place Monge au cinquième étage, leur chez soi pour le reste de leur vie.

À partir de 1962, Réa joue un rôle crucial dans la vie matérielle et intellectuelle de Claude. Elle s'occupe de l'intendance du ménage, mais bien plus essentiel est son soutien direct au travail de l'écrivain. Claude rédige à la main, puis tape son texte au fur et à mesure à la machine. Dès que l'œuvre lui semble finie, il la confie

1. A. B. Duncan, J. H. Duffy, D. Zemmour et B. Bonhomme sont les éditeurs de l'œuvre de Claude Simon dans la Bibliothèque de la Pléiade (Gallimard, 2006 et 2013). Alastair B. Duncan a présidé l'Association des Lecteurs de Claude Simon de 2012 à 2017. David Zemmour, avec Joëlle Gleize, co-dirige les Cahiers Claude Simon depuis le numéro 11. 
à Réa qui procède à une nouvelle frappe. Mais surtout, Réa soumet l'œuvre à une première lecture critique. "Ma femme est bien plus intelligente que moi ", disait Simon. Et cette intelligence s'alliait à une très grande sensibilité littéraire. Le roman tapé une nouvelle fois à la machine et lu, il arrivait à Réa et Claude d'en débattre, Réa lui faisant part de ses remarques, fondées, disait-elle, au point que Claude n'avait guère d'autre choix que d'en convenir, même si les corrections étaient pour la plupart mineures. C'est elle enfin qui apporte le tapuscrit à Jérôme Lindon aux Éditions de Minuit. Vers la fin de la vie de Claude, le soutien de Réa devient de plus en plus important. Sans sa présence aux côtés de son mari, il n'est pas du tout sûr que la belle floraison des dernières années - Le Jardin des Plantes et Le Tramway - eût pu voir le jour.

Dans chaque circonstance de la vie, Réa s'engageait pour l'œuvre de son mari. Ce travail de défense de l'œuvre devenait de plus en plus important à mesure que la santé de Claude se dégradait. Pendant le temps long de préparation des deux volumes de la Pléiade, elle lisait et commentait les brouillons de notices, toujours à l'affût des erreurs factuelles, demandant constamment de veiller à distinguer entre les idées de Claude et les interprétations personnelles.

L'Association des Lecteurs de Claude Simon (ALCS) lui doit une reconnaissance particulière. Elle suivait ses activités de près avec un œil critique mais sans jamais se départir d'une bienveillante générosité. Elle autorisait la publication de textes, de lettres et de photos aussi bien dans les Cahiers Claude Simon que sur le site web. Elle a accepté que son nom et celui de son mari soient associés au prix que l'ALCS décerne aux jeunes chercheurs simoniens.

Au cours de ces années d'échanges, tous ceux qui travaillaient avec Réa ont appris non seulement à l'admirer mais à l'aimer. Pour la vivacité de ses réactions et le bien-fondé de ses jugements, pour son exigence et son tact, pour les encouragements et les accords scellés autour d'un verre fraternel, pour la généreuse affection qu'elle a su prodiguer aussi bien à ses visiteurs qu'à son chat.

Les critiques simoniens ne peuvent que lui être infiniment reconnaissants pour la confiance et la bienveillance qu'elle n'a jamais cessé de leur manifester, accueillant et écoutant le chercheur reconnu comme le thésard inexpérimenté et tout impressionné avec le même intérêt non feint. L'un et l'autre avaient vite fait de devenir ses amis et, très vite, ils partageaient avec elle une complicité qui allait au-delà de leur admiration commune pour l'œuvre de Claude.

Sa disparition nous affecte profondément.

Quant aux Cahiers, ils n'auront d'autre ambition que de maintenir le degré d'engagement et d'exigence qui fut toujours le sien. 